\title{
DIRECT DEMONSTRATION OF SUPEROXIDE ANION PRODUCTION DURING THE OXIDATION OF REDUCED FLAVIN AND OF ITS CATALYTIC DECOMPOSITION BY ERYTHROCUPREIN ${ }^{1}$
}

David Ballou, Graham Palmer, and Vincent Massey

Department of Biological Chemistry, and Biophysics Research Division Institute of Sclence and Technology, University of Michigan, Ann Arbor, Michigan

Received July 11, 1969

SUMMARY The oxidation of reduced flavins by molecular oxygen at neutral to alkaline $\mathrm{pH}$ produces substantial yields of the superoxide anion, $0,-$. This species is rapidly destroyed by catalytic quantities of the copper protein, erythrocuprein, and by stoichiometric quantities of ferricytochrome c.

The involvement of superoxide anion in the aerobic reduction of cytochrome $\underline{c}$ catalyzed by xanthine oxidase and other metalloflavoproteins has been strongly suggested by the work of Fridovich and his colleagues $(1,2,3)$. More recently, Knowles et al. (4) have demonstrated directly, by means of the rapid-freezing EPR (electron paramagnetic resonance) technique (5), that $\mathrm{O}_{2}=$ is indeed a product of the oxidation of substrate-reduced xanthine oxidase. McCord and Fridovich (6) have recently provided strong evidence that erythrocuprein is a potent superoxide dismutase and that it inhibits the xanthine oxidase catalyzed aerobic reduction of cytochrome $c$. In both the work of Knowles et a1. (4) and the earlier work of Fridovich et al. it was suggested that the iron-sulfur component, rather than the flavin moiety, of these enzymes is responsible for the observed one electron reduction of oxygen. However, the observation that many metal free flavoproteins can catalyze an oxygen-dependent substrate-linked reduction of cytochrome $\underline{c}$ (7), which is inhibited by erythrocuprein, has led to the suggestion that reduced flavin can reduce oxygen to superoxide anion.

${ }^{1}$ Supported by NIH Grants GM 12176 and GM 11106, NIH Predoctoral Fellowship GM 39-480 (D.B.) and Career Development Award GM 31-213 (G.P.) 
In this paper we wish to report the direct demonstration that superoxide anion is produced in substantial yields during the oxidation of reduced flavins by molecular oxygen. Furthermore, the superoxide anion so produced has been shown to react rapidly with cytochrome $c$ and to be decomposed extremely rapidly by catalytic quantities of erythrocuprein.

\section{METHODS AND MATERIALS}

Erythrocuprein was isolated from beef erythrocytes by the methods of Reed et a1. (8), and was the generous gift of Dr. D. E. Hultquist and Mr. P. Passon. Its concentration was estimated from the molar extinction coefficient of 350 at $665 \mathrm{mu}$ (9). Cytochrome c, type III, was obtained from the Sigma Chemica1. Company, and tetra-acetyl riboflavin (TARF) was synthesized by the method of Hemmerich (10).

Reduced flavin solutions were prepared (and stored) under nitrogen in glass tonometers by irradiation with visible light in the presence of 1.33 $\times 10^{-2} M$ EDTA (11). Buffers were oxygenated by equilibration with oxygen (1 atm) at room temperature and stored in tonometers.

Rapid spectrophotometric studies were performed with a Gibson-Milnes stopped-flow spectrophotometer (12). Flavin oxidation was monitored at $500 \mathrm{~nm}$. The rapid-freezing technique of Bray (5) with modification by Ballou and Palmer (13) was employed to isolate the superoxide radical. Reaction of the superoxide radical with either erythrocuprein or cytochrome c was followed by employing a three syringe system (14) with subsequent rapid freezing at desired times. The plastic connecting hoses $\left(0.022^{\prime \prime}\right.$ and $0.046^{\prime \prime}$ bore, Bel Art Plastics) carrying the reduced flavin were maintained anaerobic by encasing them with thin-walled stainless steel sleeving. Repeated evacuation followed by flushing with oxygen-free helium in a desicator was carried out to minimize oxygen contamination.

EPR measurements were carried out with a Varian V4500-10A spectrometer equipped with a cryogenic device similar to that described by Hansen et al. (15). 


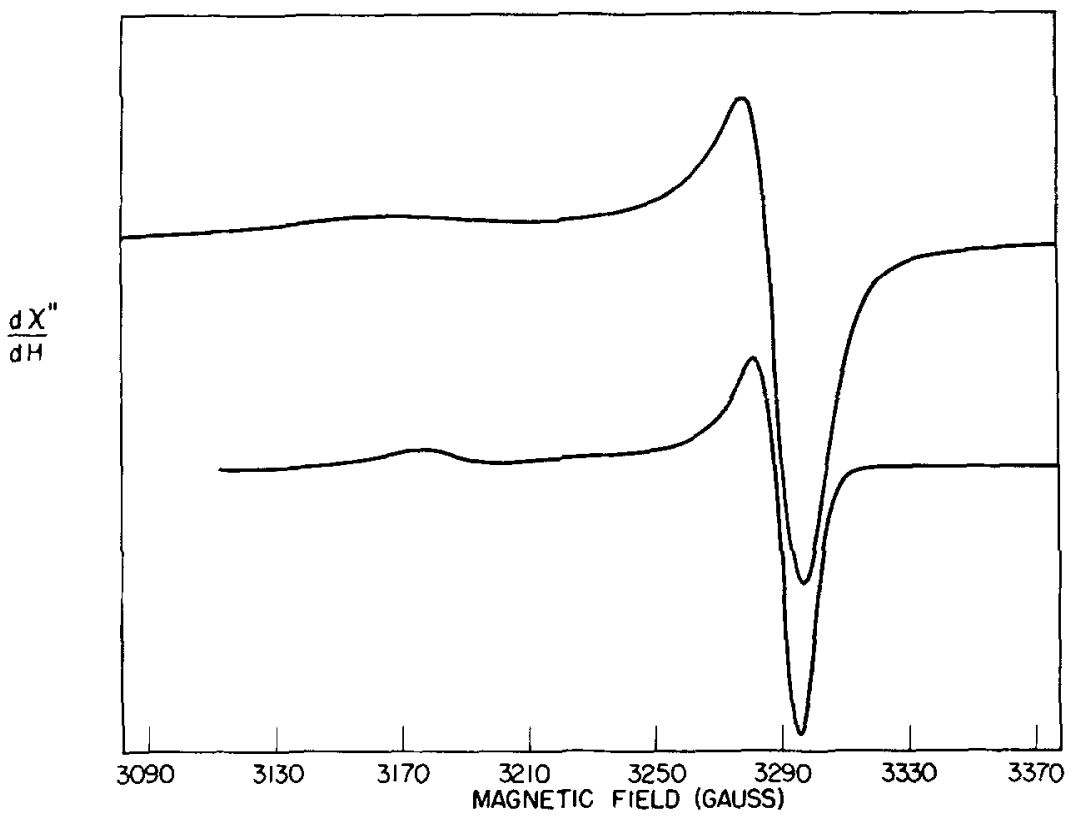

Figure 1 EPR spectra of $\mathrm{O}_{2}:$. (Top) Radical produced by the reaction of $0.075 \mathrm{M} \mathrm{KIO}_{4}$ with ${ }^{2} 0.15 \mathrm{M} \mathrm{H}_{2} \mathrm{O}_{2}$ in $0.1 \mathrm{M}$ glycine buffer $\mathrm{pH} 9.9$ at $20^{\circ}$ for $545 \mathrm{msec}$. EPR spectrum recorded at $87^{\circ} \mathrm{K}$. (Bottom) Radical produced by reaction of $1.25 \times 10^{-4} \mathrm{M} \mathrm{TARFH}_{2}$ with 6.25 $\mathrm{x} 10^{-4} \mathrm{M}$ oxygen in $0.095 \mathrm{M}$ glycine $\mathrm{pH} 10.6$ at $20^{\circ}$ for $444 \mathrm{msec}$. EPR spectrum recorded at $92^{\circ} \mathrm{K}$. Microwave power, $3 \mathrm{~m}$ watts; modulation amplitude, 3 gauss at $100 \mathrm{kHz}$. Microwave frequency $9.235 \mathrm{GHz}_{\mathrm{z}}$.

\section{$\underline{\text { RESULTS }}$}

Figure 1 shows EPR spectra of the oxygen radical trapped by rapid freezing during both the reaction of reduced tetra-acety 1 riboflavin (TARFH ${ }_{2}$ ) and $0_{2}$, and the reaction of $\mathrm{KIO}_{4}$ and $\mathrm{H}_{2} \mathrm{O}_{2}$. A similar spectrum was obtained by the reaction of dithionite with oxygen (4). The g-values and overall shape of the spectra are in close agreement with those obtained by knowles et al. (4) in the $\mathrm{KIO}_{4}$ vs $\mathrm{H}_{2} \mathrm{O}_{2}$ system and in the xanthine oxidase reaction. They also agree well with those obtained by Ichikawa et al. (16) and Bennett et al. (17) who report values of $g_{11}=2.088$ and $g_{1}=2.008$.

Similar spectra were also obtained for the reaction of reduced FMN with $\mathrm{O}_{2}$, but flavin impurities in the sample made kinetic analysis less straightforward than with $\mathrm{TARFH}_{2}$ which was therefore used in the studies reported here. 


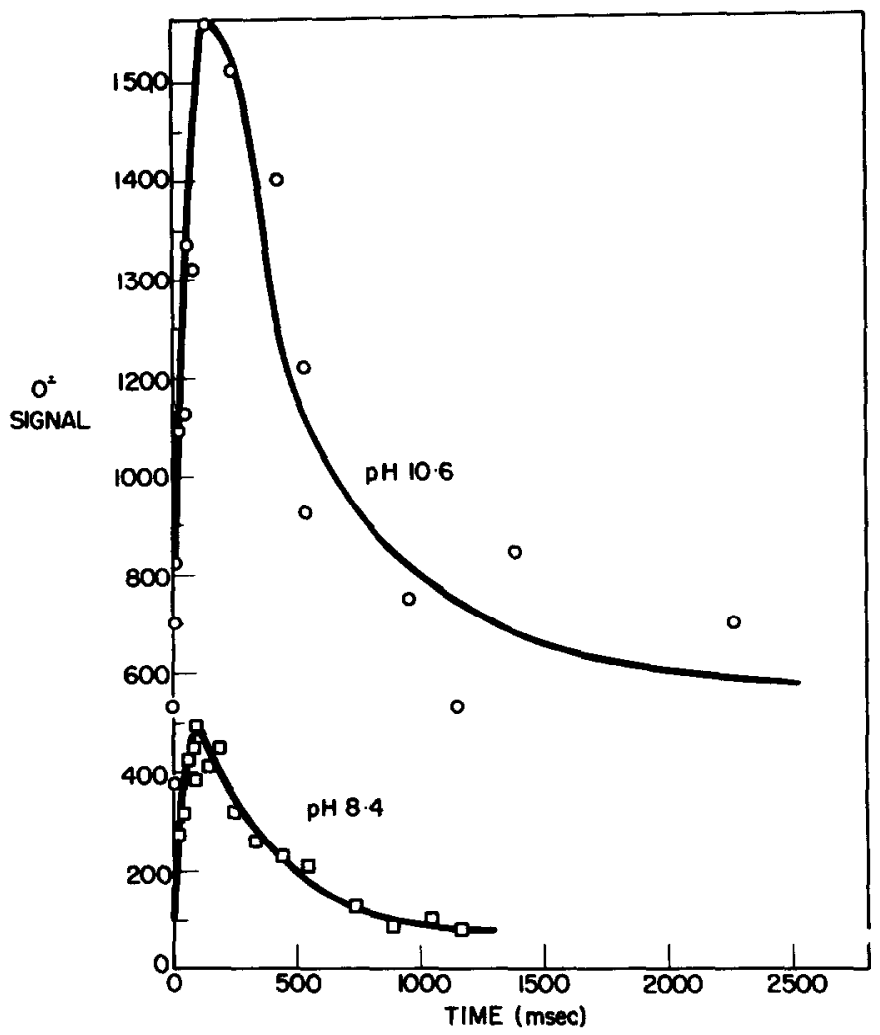

Figure 2 Time course of the appearance and decay of $0_{2}:$ produced by reaction of $1.25 \times 10^{-4} \mathrm{M}^{\mathrm{TARFH}}{ }_{2}$ and $6.5 \times 10^{-4} \mathrm{M} \mathrm{O}_{2}$ at $20^{\circ}$. Top curve, in $0.1 \mathrm{M}$ glycine $\mathrm{pH} 10.6$. Bottom curve, in $0.1 \mathrm{M}$ glycylglycine $\mathrm{pH}$ 8.4. All times include the $5 \mathrm{msec}$. quenching time. Maximum intensity at $\mathrm{pH} 10.6$ corresponds to $1.19 \times 10^{-4} \mathrm{M}$ oxygen radical. Modulation amplitude 10 gauss at $100 \mathrm{kHz}$. Microwave power $=12 \mathrm{~m}$ watts. Microwave frequency $=9.2 \mathrm{GHz}$. Temperature $=84^{\circ} \mathrm{K}$.

It was found that the kinetics and the yield of the $0_{2}=$ radical were markedly affected by $\mathrm{pH}$. Figure 2 shows the kinetic progress curves for identical reactions of $\mathrm{TARFH}_{2}$ with oxygenated buffer at $\mathrm{pH} 10.6$ and $\mathrm{pH} 8.4$. The most striking feature is the difference in the yields of the radical species produced at the two $\mathrm{pH}$ values. At $\mathrm{pH} 10.6$ the maximum yield (obtained by double integration using a copper sulfate - EDTA standard) was $96 \%$ of the initial reduced flavin concentration whereas at $\mathrm{pH} 8.4$ the maximum yield was on 1 y $14 \%$. Although the decay of the radical species is slower at the higher $\mathrm{pH}$, this factor alone cannot account for the difference 
in yields. This result suggests that the superoxide anion reacts only slowly with reduced flavin species at the higher $\mathrm{pH}$ whereas it reacts much more readily at the lower $\mathrm{pH}$. That $\mathrm{O}_{2}-$ is involved in the autocatalytic reoxidation of reduced flavin was shown by stopped-flow studies; in the presence of $10^{-7} \mathrm{M}$ erythrocuprein the reoxidation of $\mathrm{TARFH}_{2}$ by $\mathrm{O}_{2}$ was slowed down four-fold. These results will be published in full later.

Having obtained direct evidence that oxidation of reduced flavins can produce substantial amounts of the superoxide anion, it became desirable to confirm directly the proposal that erythrocuprein is a superoxide dismutase (1). Rapid-freezing studies were performed employing a three syringe system which produced the superoxide radical by the reaction at $\mathrm{pH} 8.4$ of $\mathrm{TARFH}_{2}$ and $\mathrm{O}_{2}$ contained in the first two syringes respectively, and, after a delay of 181 msec., introduced erythrocuprein via the third syringe. By varying the dead volume from the second mixing chamber to the exit nozzles, a kinetic progress curve of the reaction catalyzed by erythrocuprein could be obtained. Stopped-flow studies showed that more than $98 \%$ of the flavin had been oxidized at the time at which erythrocuprein was introduced. It can be seen from Figure 2 that at $181 \mathrm{msec}$. nearly $80 \%$ of the maximum yield of superoxide anion (or about $2 \times 10^{-5} \mathrm{M}$ ) was available for reaction with erythrocuprein. At erythrocuprein concentrations greater than $6.2 \times 10^{-7} \mathrm{M}$, no superoxide radical could be detected at times longer than $12 \mathrm{msec}$ after introduction of erythrocuprein. (This includes the $5 \mathrm{msec}$. necessary for quenching (13).)

Iimited kinetic studies of the decomposition of superoxide anion by this direct method are shown in Figure 3. The decay of the superoxide signal followed second order kinetics implying that at this concentration of $\mathrm{O}_{2}=$ the erythrocuprein is not saturated with substrate. Under these experimental conditions (i.e. with limiting $\mathrm{O}_{2}=$ concentrations), the turnover number for erythrocuprein as a superoxide anion dismutase can be estimated to be at least 3 million (moles $0_{2}$ - disappearing per minute per mole erythrocuprein). When in this three syringe experiment the exythrocuprein was replaced 


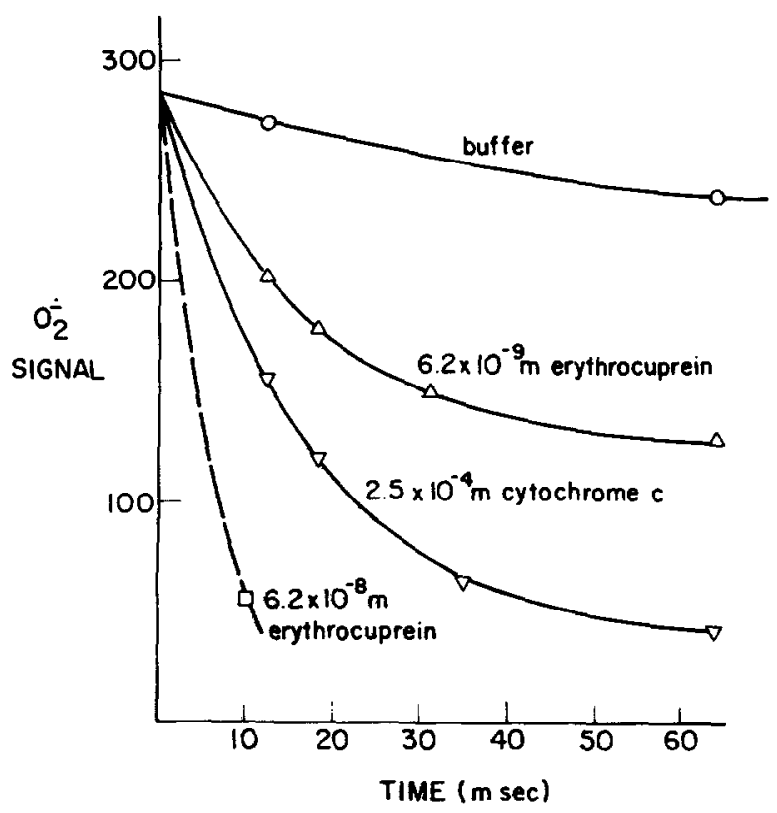

Figure 3 Reaction of $\mathrm{O}_{2}$ - with erythrocuprein and cytochrome c. $0_{2}=$ was produced by the reaction of $1.25 \times 10^{-4} \mathrm{M}$ TARFH 2 with $6.5^{2} \times 10^{-4} \mathrm{M}$ $\mathrm{O}_{2}$ in $0.1 \mathrm{M}$ glycylglycine $\mathrm{pH} 8.4$ at $20^{\circ}$ for $181 \mathrm{msec}$, before reaction from a third syringe with erythrocuprein, cytochrome $c$, or buffer as shown. The reaction times shown are those from $181 \mathrm{msec}$. and include the $5 \mathrm{msec}$. quenching time. The signal intensities in this experiment are $67 \%$ of those reported in Figure 2 (bottom) because of the dilution produced by the third syringe. Modulation amplitude 10 gauss at $100 \mathrm{kHz}$. Microwave power $=12 \mathrm{~m}$ watts. Microwave frequency $9.2 \mathrm{GHz}$. Temperature $=$ $84^{\circ} \mathrm{K}$.

with cytochrome $c$, rapid disappearance of $\mathrm{O}_{2}$ - was again observed (Figure 3 ). The decay of the $\mathrm{O}_{2}$ - signal follows first order kinetics with a pseudo first order rate constant of $40 \mathrm{sec}^{-1}$ which is equivalent to a second order rate constant of $1.6 \times 10^{5} \mathrm{M}^{-1} \mathrm{sec}^{-1}$.

In summary these observations provide direct experimental proof that $\mathrm{O}_{2}=$ is a significant product in the reaction of oxygen with reduced flavins, and that it can be rapidly decomposed by erythrocuprein. By the above techniques it should be possible to investigate the role of $\mathrm{O}_{2}=$ in a wide range of biological oxidation-reduction reactions. 


\section{ACKNOWLEDGEMENTS}

We are indebted to Mr. P. Passon and Dr. D. E. Hultquist for the gift of erythrocuprein, to G. Gruell for preparing TARF and to Dr. J. Fee for valuable discussions.

\section{REFERENCES}

1. Fridovich, I., and Handler, P., J. Biol. Chem. 233, 1578 (1958).

2. Fridovich, I., and Handler, P., J. Biol. Chem. $\overline{233}, 1581$ (1958).

3. Fridovich, I., and Handler, P., J. Biol. Chem. $\overline{236}, 1836$ (1960).

4. Knowles, P. F., Gibson, J.F., Pick, F. M., and Bray, R. C., Biochem. J. 111,53 (1969).

5. Bray, R. C., Biochem. J. 81,189 (1961).

6. McCord, J. M., and Fridovich, I., Fed. Proc. 28, 346 No. 492 (1969).

7. Massey, V., Strickland, S., Mayhew, S. G., Howe11, L. G., Engel, P. C., Matthews, R. G., Schumann, M., and Sullivan, P. A., Biochem. Biophys. Res. Comm. (accompanying paper).

8. Reed, D. W., Passon, P. G., and Hultquist, D. E., J. Biol. Chem. (submitted).

9. Stanse11, M. J., and Deutsch, H. F., J. Biol. Chem. 240, 4306 (1965).

10. Hemmerich, P., Helv. Chem. Acta 47, 664 (1966).

11. Frise11, W. R., Chung, C. W., and McKenzie, C. G., J. Bio1. Chem. 234, 1297 (1959).

12. Gibson, Q. H., and Milnes, L., Biochem. J. 91,161 (1964).

13. Ballou, D. P., and Palmer, G., to be published.

14. Palmer, G., Bray, R. C., and Beinert, H., J. Biol. Chem. 239, 2657 (1964).

15. Hansen, R., Kala1, J., and Beinert, H., Anal. Biochem. 20, 10 (1967).

16. Ichikawa, T., Iwasaki, M., Kuwata, K., J. Chem. Phys. 44, 2979 (1966).

17. Bennett, J. E., Mile, B., and Thomas, A., Trans. Farad. Soc. 64, 3200 (1968). 